\title{
A Microscopy and FTIR and PL Spectra Study of Polycrystalline Diamonds from Mengyin Kimberlite Pipes
}

\author{
Zhijun Yang, ${ }^{1,2}$ Rong Liang, ${ }^{1}$ Xiangqing Zeng,, ${ }^{1}$ and Mingsheng Peng1 \\ ${ }^{1}$ Department of Earth Science, Sun Yat-Sen University, Guangzhou 510275, China \\ ${ }^{2}$ Guangdong Provincial Key Laboratory of Mineral Resource Exploration \& Geological Processes, Guangzhou 510275, China
}

Correspondence should be addressed to Zhijun Yang, yzjdoctor@163.com

Received 1 March 2012; Accepted 26 March 2012

Academic Editors: P. Malý, J. Misiewicz, and A. Polimeni

Copyright ( 2012 Zhijun Yang et al. This is an open access article distributed under the Creative Commons Attribution License, which permits unrestricted use, distribution, and reproduction in any medium, provided the original work is properly cited.

\begin{abstract}
The results of a microscopy and FTIR and PL spectra study of the natural polycrystalline diamonds from the Mengyin kimberlite pipes show that they can be classified as the euhedral faceted polycrystalline diamonds (EFPCDs) and anhedral rounded polycrystalline diamonds (ARPCDs). Different diamond grains or their points were formed in different conditions or processes. They were not formed in diamond nucleation stage, but in the diamond growth period. They probably originated from the relatively deeper mantle and were formed in the environment like the peridotitic $(\mathrm{P})$ type diamond single crystals. The EFPCDs did not undergo a remarkable dissolution process during their formation and were possibly fast formed shortly before the kimberlite eruption. The ARPCDs not only were formed at a higher temperature than the EFPCDs but also underwent a notable dissolution process and had been stored relatively longer in the mantle. Fluids or melts probably participated in the formation of the ARPCDs or modified them during the period of their storage in the mantle.
\end{abstract}

\section{Introduction}

Polycrystalline diamonds are multigranular aggregates consisting almost entirely of diamonds. Based on the qualitative external characteristics, there are many and diverse polycrystalline varieties of diamond. Among them, balas displaying radial fibrous structure is spherulite, bort is a distinctly granular aggregate, and carbonado consisting of submicroscopic diamond particles is a cryptocrystalline aggregate [1]. But based on the scientific origin of the natural polycrystalline diamonds, previous studies [2] classified them as carbonado and framesite. Carbonado is multigranular and porous sensu stricto refers specifically to the diamond aggregates from the Central African Republic and Brazil, and it has been found that most of them occur in placers [3]. Framesite is used more broadly to describe clusters of randomly oriented microcrystalline diamonds found in association with the kimberlites all over the world. In addition, framesite is also called diamondite, which is a monomineral rock consisting almost entirely of diamonds and minor amount of other minerals such as silicate and sulfide $[4,5]$.
Study on the polycrystalline diamonds has not only important scientific significance but also notable practical value. Firstly, in the polycrystalline diamonds, there are randomly oriented microcrystalline diamond grains and high densities of grain boundaries which effectively impede the fracture propagation of the (111) cleavage in diamonds, so their hardness, toughness, and wear resistance are higher than those of the single-crystal diamonds. This is also the main reason why the polycrystalline diamonds have been widely used in drill bits, cutting tools, drawing dies, wear devices, and so forth. Currently, the research of the synthetic polycrystalline diamonds has become an international hotspot and frontier subject, particularly in the field of hardness and toughness improvement of diamond [6]. Secondly, the suite of inclusions in the polycrystalline diamonds is obviously different from that in the diamond single crystals, which indicates that it is very difficult to explain the formation of the polycrystalline diamonds using the established modes of the genesis of the single-crystal diamonds [2]. For instance, typical peridotitic (P) type inclusion minerals such as olivine and orthopyroxene have not been found in the polycrystalline diamonds so far and 
the typical eclogitic (E) type inclusion mineral, namely, omphacitic clinopyroxene, is very rare. On the other hand, kosmochlor-rich clinopyroxene with very high $\mathrm{Cr}_{2} \mathrm{O}_{3}$ contents $(10-11 \mathrm{wt} \%)$ is described only from the polycrystalline diamonds and has never been found as an inclusion in the single crystal diamonds [5]. Thirdly, the research of the natural polycrystalline diamonds has become an effective approach to analyzing the formation and origin of diamonds and investigating the major scientific issues in the deep earth such as the cratonic lithosphere remobilization [3-5, 7-9].

Although there is no doubt that the framesites are derived from the kimberlite pipes which are sampled from the earth deep interior and almost all researchers attribute the fine grain size of the framesites to rapid crystallization in localized areas of the mantle containing high concentrations of carbon and incompatible and volatile elements [2], so far the formation mechanism of the polycrystalline diamonds is still a hotly debated subject and detailed formation (nucleation and growth) histories of the polycrystalline diamonds are still poorly known. Based on the geochemical indicators for the formation of the polycrystalline diamonds, some researchers invoke the subduction of the ocean floor and its subsequent mixing with the upper mantle lithosphere as a mechanism for the framesite crystallization $[10,11]$. Some researchers suggest the remobilization of older carbon and silicate components to form the framesites shortly before the kimberlite eruption [7]. Others conclude that diamondites are the product of rapid crystallization from water and/or carbonate-dominated fluid [4] and fluidrock fraction processes rather than the igneous fractional crystallization processes are responsible for the evolution of the diamondite-forming fluids [5]. Based on the research results of the formation of the pure polycrystalline diamonds by direct conversion of graphite at high pressure and high temperature, some researchers imply that the natural polycrystalline diamonds may have been formed by a rapid transformation from the metastable graphite present in the cold subducted crust, when encountering the warmer regions, such as rising plumes in the mantle transition region [6]. With regard to the different formation models of the framesites, what exactly is the reason for the controversy over the formation of the framesites? The present authors speculate this may be related to the fact that the framesites have been treated as a homogeneous system. In fact, despite the fact that almost all researchers attribute the fine grain size of the framesites to rapid crystallization, the framesites are actually inhomogeneous and the different growth zones of the framesites have different components and structures because of varying conditions (such as impurity, pressure, temperature, oxygen fugacity, and crystallization velocity) for the formation of the natural polycrystalline diamonds. Furthermore, the formation of the polycrystalline diamonds is associated with the driving force and medium for the aggregation of diamond grains and certain conditions to preserve the polycrystalline diamonds once formed. In a word, an accurate formation mechanism should be based on the results of analyzing microcomposition and microstructure and recovering the history of nucleation and growth of the polycrystalline diamonds.

\section{Sample and Experiment}

In this paper we focus on the natural polycrystalline diamonds (framesites) from the Mengyin kimberlite pipes. We consider them as a set of microvolumes that are formed at different times. Thus, we characterize their microtopography, microcomposition, and microstructure by using an optical microscope, Fourier transform infrared spectra (FTIR), and photoluminescence spectra (PL) from point to point and discuss their significance to the formation and origin of the framesites.

The natural polycrystalline diamonds (framesites) were selected from the kimberlite diatremes in the Mengyin diamond mine, Shandong province, which is one of the primary diamond mines in China. The Mengyin kimberlite breccia pipes are located in the eastern part of the North China Craton (Figure 1).

An optical microscope was used to characterize the crystal habit and surface topographic images of the fresh samples.

The micro-FTIR absorption spectra were recorded on the rough samples from $500 \sim 4000 \mathrm{~cm}^{-1}$ with $4 \mathrm{~cm}^{-1}$ resolution and 128 times scan at liquid nitrogen temperature (LNT) in transmission mode using a Bruker EQUINOX-55 FTIR spectrometer coupled with an infrared microscope. The FTIR spectra were recorded in some points located at different diamond grains or positions of the same polycrystalline diamonds. Namely, the FTIR spectra were recorded in different diamond grains of the euhedral faceted polycrystalline diamonds (EFPCDs) and in different positions on the anhedral rounded polycrystalline diamonds (ARPCDs).

A Renishaw InVia Confocal Micro-Raman spectrometer was employed for the photoluminescence analysis, using excitation by the $514.5 \mathrm{~nm}$ line of an $\mathrm{Ar}^{+}$laser. The PL spectra were recorded from $1.3 \sim 2.4 \mathrm{eV}$ at LNT with $2 \mu \mathrm{m}$ light spot diameter and $1 \mu \mathrm{m}$ depth value error, from the surface to the depth of $-200 \mu \mathrm{m}$ at intervals of $50 \mu \mathrm{m}$ in the different points of the ARPCDs, and from the surface to the depth of $-200 \mu \mathrm{m}$ or $-160 \mu \mathrm{m}$ at intervals of $50 \mu \mathrm{m}$ or $40 \mu \mathrm{m}$ in the different diamond grains of the EFPCDs.

\section{Results}

3.1. Optical Microscopy. Figure 2 shows the typical optical microscopic photographs of the polycrystalline diamonds. The size of the polycrystalline diamonds samples (Figures 2 (a) and 2(b)) varies from $1 \mathrm{~mm}$ to $2.5 \mathrm{~mm}$ with masses from $4 \times 10^{-3}$ to $1 \times 10^{-2}$ gram (0.02 to 0.05 carat). The color of the bulk samples varies from colorless (clear) to shades of grey to yellow to almost black. In one sample, the diamond grains have similar colors. Most of the samples are translucent or subtranslucent, and a minority of them are transparent. Most of them have adamantine luster. On the whole, the samples can be classified as the EFPCDs and ARPCDs.

In the EFPCDs, the individual diamond grains have an octahedral habit and are randomly oriented and their sizes vary among the samples from $200 \mu \mathrm{m}$ to $1 \mathrm{~mm}$ (Figure 2(d)). The centers of some diamond grains are 


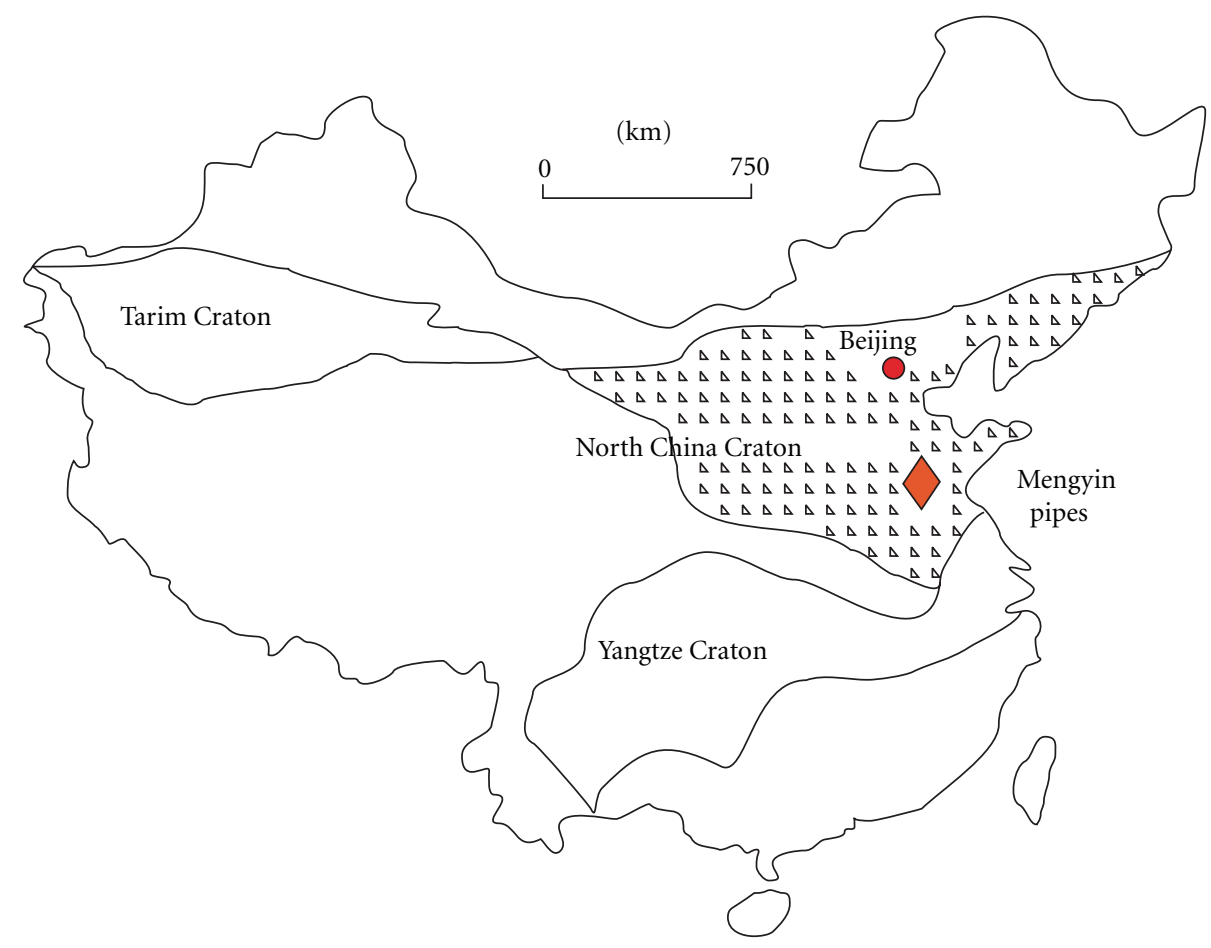

FIGURE 1: Sketch map of P. R. China, showing the location of the North China Craton, and the locality of the Mengyin kimberlite pipes [after Wuyi Wang et al., 1998 [12] with modification].

included in other diamond grains, whereas those of the others are not (Figure 2(d)). On the (111) surface of diamond grains, there are abundant growth lamellae and zigzag strips (Figure $2(\mathrm{~d}) \sim$ Figure $2(\mathrm{f})$ ). In addition, there are screw growth striations (Figure $2(\mathrm{~g})$ ) and stacked triangular lamellae of successively decreasing size (Figures 2(f) and $2(\mathrm{~h})$ ) on the (111) surface of some diamond grains. It is worth further noticing that the diamond grain (Figure 2(e)) displays microcorrugated combination surfaces with striations parallel to the octahedral edges if thin lamellae develop on (111) faces and their edges are closely crowded together. In position, the individual sections of the uneven combination surfaces correspond to a series of distinct trigonal trisoctahedrons and in some special cases to the faces of a rhombic dodecahedron.

Most of the ARPCDs are elliptic-like aggregates, and a minority of them are composed of sharp-edged diamond grains with smooth cured surface. On the surface of the ARPCDs, there are irregular pits with parallel striation floors (Figure 2(i)), circular striations and protruding disks (Figure 2(j)), protruding guttate overgrown hillocks (Figure 2(k)), and streak and imbricate structures (Figures $2(\mathrm{l})$ and $2(\mathrm{~m}))$. In addition, the ARPCDs are complex intergrowths of anhedral diamonds with abundant interstitial pores and cavities (Figures 2(n) and 2(o)).

3.2. Fourier Transform Infrared Spectroscopy. In the pure natural diamond, only two phonon absorption processes are infrared-active, but the presence of impurities such as nitrogen, hydrogen, boron and/or defects in structure cause the forbidden single-phonon mode to become infrared active [13]. So one can always find absorption bands in $<1332 \mathrm{~cm}^{-1}, \quad 1900 \sim 2500 \mathrm{~cm}^{-1}$, and $2800 \sim 3800 \mathrm{~cm}^{-1}$ regions in the IR spectra of the diamond. In the FTIR spectra of the samples (Figure 3), absorption bands in $1900 \sim 2500 \mathrm{~cm}^{-1}, 2800 \sim 3800 \mathrm{~cm}^{-1}$, and $<1332 \mathrm{~cm}^{-1}$ and $\sim 1360 \mathrm{~cm}^{-1}$ regions are respectively attributed to the diamond intrinsic absorption, hydrogen-related absorption, and nitrogen-related absorption.

In the hydrogen-related absorption bands, the $~ 3107$ $\mathrm{cm}^{-1}$ absorption peak is attributed to the stretching vibration of vinylidene group $\left(>\mathrm{C}=\mathrm{CH}_{2}\right)$, the $\sim 2923 \mathrm{~cm}^{-1}$, $\sim 2854 \mathrm{~cm}^{-1}$ peaks are due to the asymmetrical and symmetrical stretching vibration of $\mathrm{sp}^{3}$-hybridized $\mathrm{C}-\mathrm{H}$ bonds [13-15], and the $3762 \mathrm{~cm}^{-1}$ and $\sim 3660 \mathrm{~cm}^{-1}$ peaks are, respectively, related to the stretching vibration of hydroxyl group and $\mathrm{H}_{2} \mathrm{O}$. Comparing the FTIR spectra of the EFPCDs (Figures 3(a) and 3(b)) with those of the ARPCDs (Figures $3(c)$ and $3(d)$ ), we find that the intensity of hydrogen-related absorption peaks of the ARPCDs is stronger than that of the EFPCDs, especially the $\sim 2923 \mathrm{~cm}^{-1}$ and $\sim 2854 \mathrm{~cm}^{-1}$ peaks are very weak in the FTIR spectra of the EFPCDs.

With regard to one EFPCD sample, the FTIR intensities of the same hydrogen-related absorption peak are nonidentical in different diamond grains (Figures $3(a)$ and $3(b)$ ). For instance, with regard to the No. FR23 EFPCD sample (Figure 3(b)), there is a $\sim 3107 \mathrm{~cm}^{-1}$ absorption peak in the FTIR spectra of the No. FR23-1, FR23-2 and FR23-3 diamond grains, but there is not any notable $\sim 3107 \mathrm{~cm}^{-1}$ FTIR absorption peak in the FR23-4 diamond grain. The $\sim 2923 \mathrm{~cm}^{-1}$ and $\sim 2854 \mathrm{~cm}^{-1}$ absorption peaks are only present in the FTIR spectra of the FR23-3 diamond grain, 


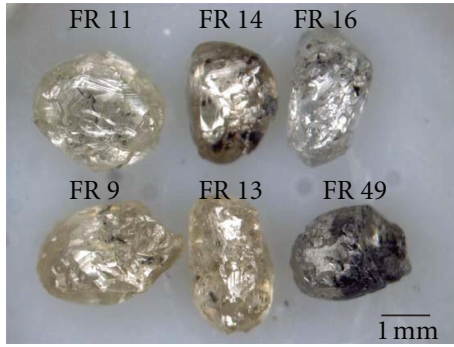

(a)

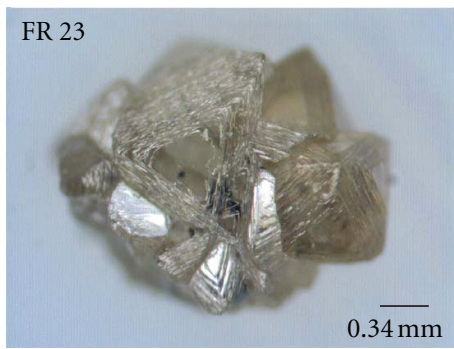

(d)

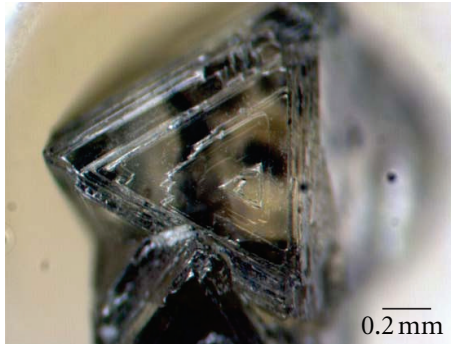

(g)

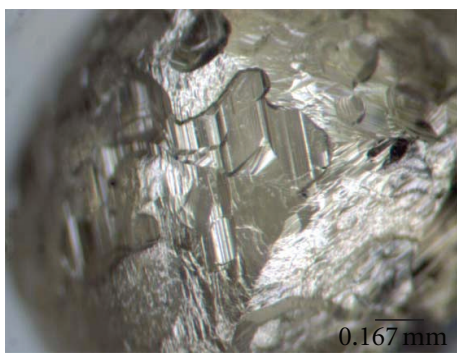

(j)

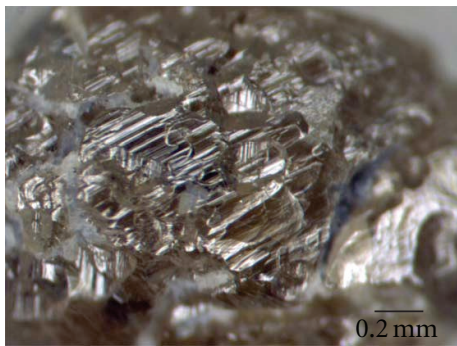

(m)

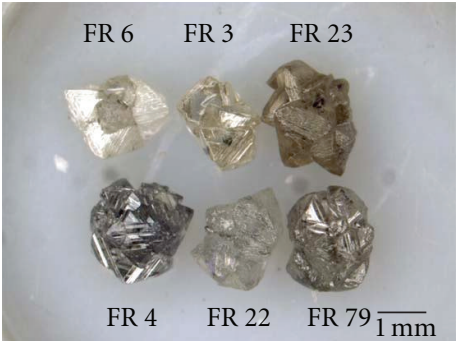

(b)

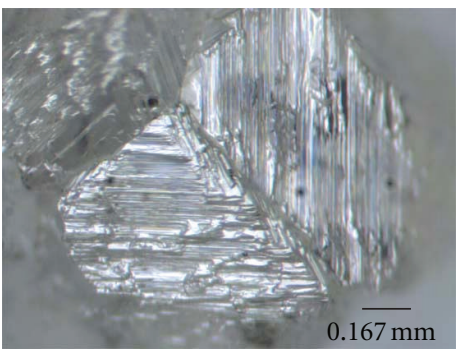

(e)

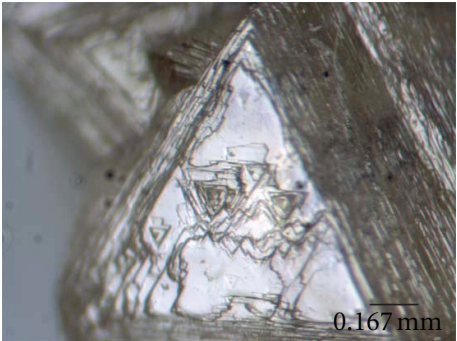

(h)

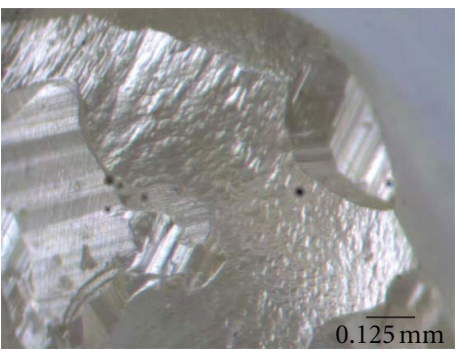

(k)

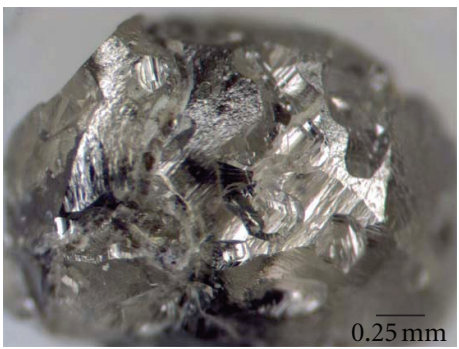

(n)

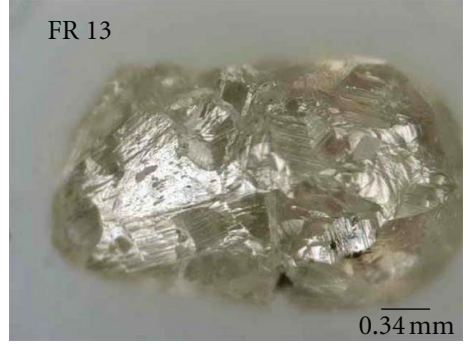

(c)

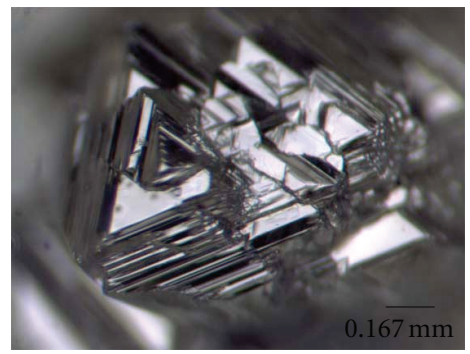

(f)

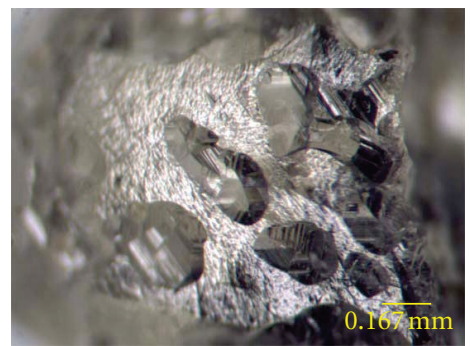

(i)

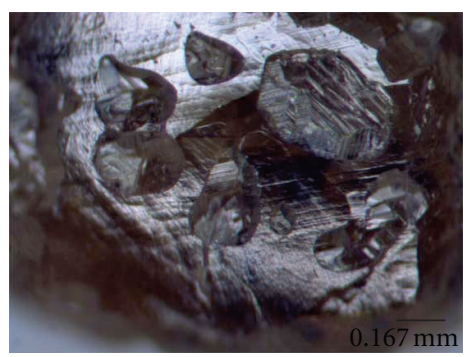

(1)

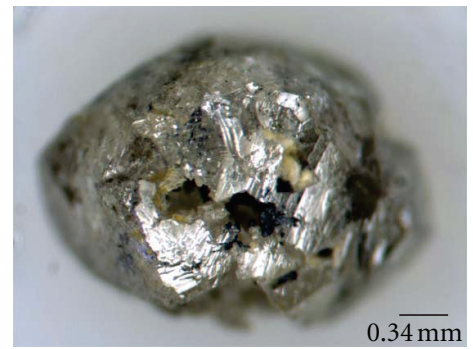

(o)

FIGURE 2: Optical stereophotographs of the polycrystalline diamonds from the Mengyin kimberlite pipes ((a) and (c) ARPCDs; (b) EFPCDs; (d), (e) and (f) growth lamellae and zigzag strips; (g) screw growth striations; (h) stacked triangular lamellae; (i) irregular pits with parallel striation floors; ( $\mathrm{j}$ ) circular striations and protruding disks; $(\mathrm{k})$ protruding guttate overgrown hillocks; (l) and (m) streak and imbricate structures; (n) and (o) complex intergrowths of anhedral diamonds with abundant interstitial pores and cavities). 


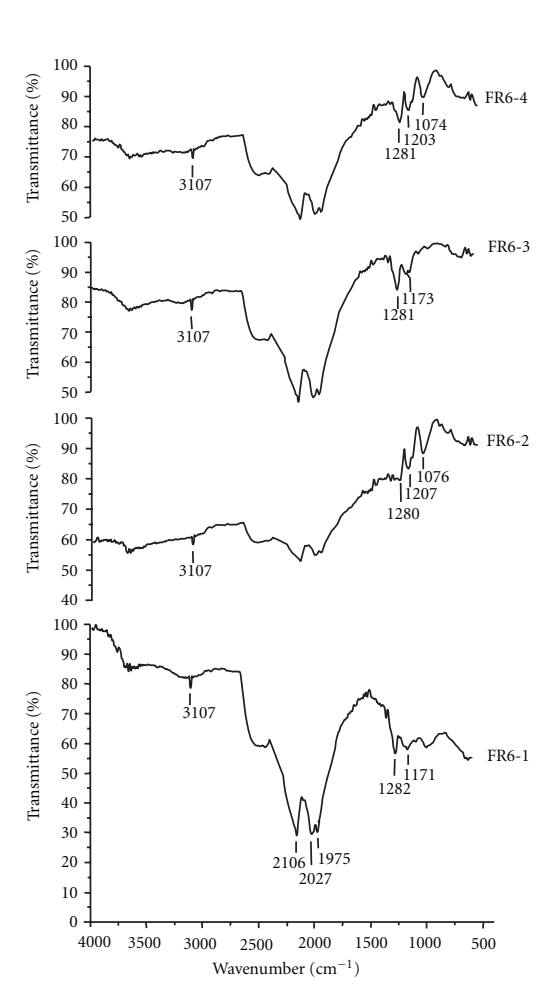

(a)
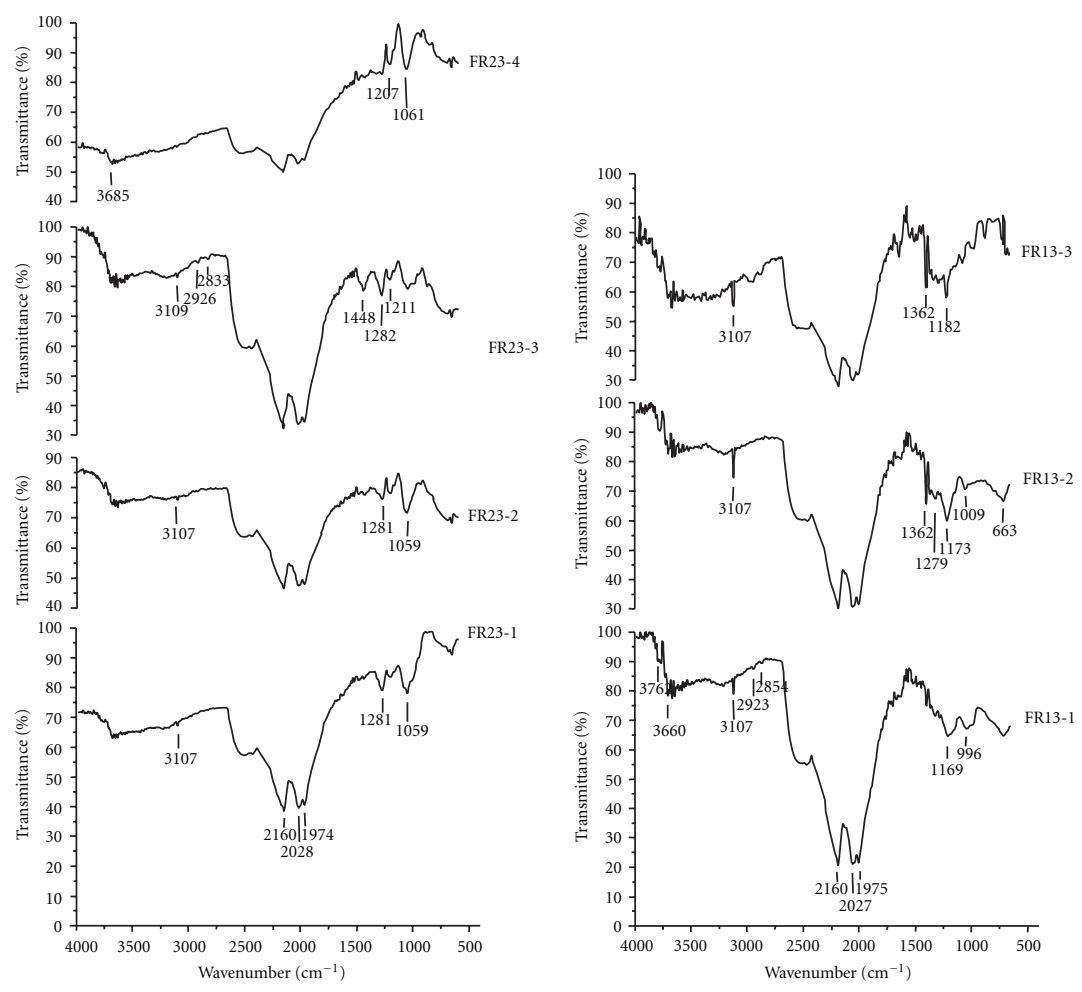

(b)

(c)

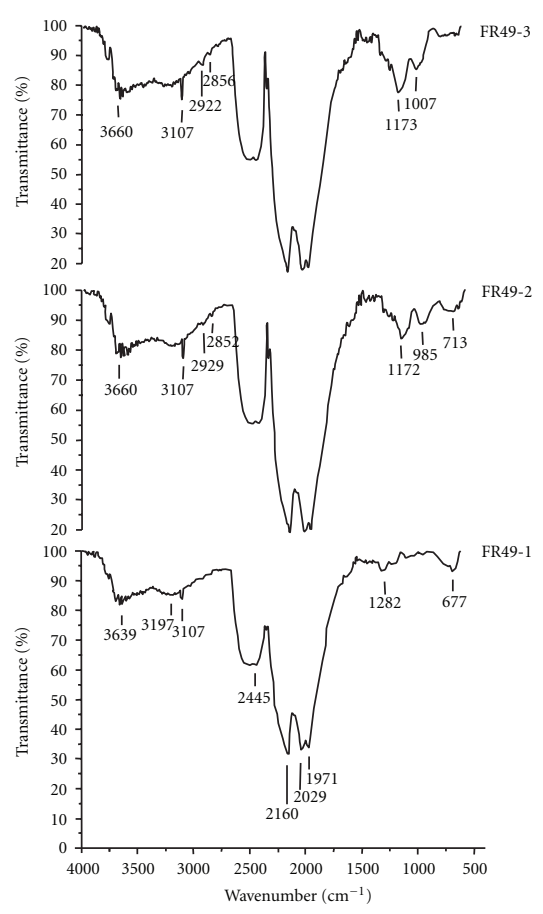

(d)

FIGURE 3: Typical FTIR spectra of the polycrystalline diamonds from the Mengyin kimberlite pipes ((a) and (b) EFPCDs; (c) and (d) ARPCDs). 
but absent in the FTIR spectra of the FR23-1, FR23-2 and FR23-4 diamond grains.

With regard to one ARPCD sample, the FTIR intensities of the same hydrogen-related absorption peak are also nonidentical in different points of the sample (Figures 3(c) and 3(d)). For example, in the FTIR spectra of the No. FR13 ARPCD sample, the $\sim 2923 \mathrm{~cm}^{-1}, \sim 2854 \mathrm{~cm}^{-1}$ absorption peaks are present in points 1 (FR13-1) and 3 (FR13-3), but absent in point 2 (FR13-2). Similarly, in the FTIR spectra of the FR49 ARPCD sample, the $\sim 2923 \mathrm{~cm}^{-1}$ and $\sim 2854 \mathrm{~cm}^{-1}$ absorption peaks are slightly stronger in points 2 (FR49-2), and 3 (FR49-3), but very weak in point 1 (FR49-1).

In the nitrogen-related absorption bands, $\sim 1280 \mathrm{~cm}^{-1}$ and $\sim 1205 \mathrm{~cm}^{-1}$ absorption peaks correspond to pairs of neighboring substitutional nitrogen (A-center, type IaA diamond), the $\sim 1175 \mathrm{~cm}^{-1}$ peak is related to complexes " $4 \mathrm{~N}+\mathrm{V}$ " (B-center, type IaB diamond), and the $\sim 1362 \mathrm{~cm}^{-1}$ peak is attributed to the platelets. The nitrogen-related absorption peaks are weak in the FTIR spectra of both the EFPCDs, and ARPCDs. Moreover, there are more B-centers and fewer A-centers in the ARPCDs than in the EFPCDs and the platelets are only present in the ARPCDs.

In one EFPCD sample, there are different types or contents of nitrogen in different diamond grains. For example, the nitrogen-related absorption bands are different in the FTIR spectra of different diamond grains of the FR23 EFPCD sample although A-centers are present in all of them (Figure 3(b)). Furthermore, in the FR6 EFPCD sample, both A-center and B-center are present in the FR6-1 and FR6-3 diamond grains, but only A-center is present in the FR6-2 and FR6-4 diamond grains.

In one ARPCD sample, there are different types of nitrogen in different points too. For instance, in the FR13 ARPCD sample, the platelets are present in points 2 (FR13-2) and 3 (FR13-3), but absent in point 1 (FR13-1). In the FR49 ARPCD sample, there is only B-center in points 2 (FR49-2) and 3 (FR49-3) and only A-center in point 1 (FR49-1).

3.3. Photoluminescence. The $514.5 \mathrm{~nm}$ lines of the Ar+ laser had excited visible to NIR PL with a lot of vibronic systems/zero-phonon lines (ZPLs) in the polycrystalline diamonds from the Mengyin kimberlite pipes (Figure 4). The signal marked " $\mathrm{R}$ " is the LO = TO Raman band of diamond, which is $1332 \mathrm{~cm}^{-1}$ from the laser line. In Figure 4, the main features are three ZPLs at $2.313 \mathrm{eV}(535.9 \mathrm{~nm})$, $2.153 \mathrm{eV}(575 \mathrm{~nm})$, and $2.024 \mathrm{eV}(613 \mathrm{~nm})$ plus broad PL bands at around $1.8 \mathrm{eV}(690 \mathrm{~nm})$ excited in different depths of the samples. The emission lines at $2.313 \mathrm{eV}(535.9 \mathrm{~nm})$ and $2.153 \mathrm{eV}(575 \mathrm{~nm})$ have been observed previously in some natural brown diamonds and can also be produced in diamonds containing nitrogen (mainly in the B form) by radiation damage and annealing at high temperature. Vibronic system with $2.153 \mathrm{eV}(575 \mathrm{~nm}) \mathrm{ZPL}$ corresponds to the $[\mathrm{N}-\mathrm{V}]^{0}[15]$. The $2.024 \mathrm{eV}(613 \mathrm{~nm})$ center can be observed in some natural type I diamonds. The broad PL bands at around $1.8 \mathrm{eV}(690 \mathrm{~nm})$ are due to the $2.024 \mathrm{eV}(613 \mathrm{~nm}) \mathrm{ZPL}$ and vibronic structure in the natural sample [16]. The PL intensities of $2.024 \mathrm{eV}(613 \mathrm{~nm})$ and $1.8 \mathrm{eV}(690 \mathrm{~nm})$ lines show notably positive correlation. In addition, the $1.673 \mathrm{eV}(743 \mathrm{~nm}) \mathrm{ZPL}$, excited just near the surface of the samples, most likely relates to the GR1 center which is the main optical feature of irradiated diamond of any type of diamonds.

In the PL spectra of one EFPCD sample (Figures 4(a) and $4(\mathrm{~b})$ ), there exist different ZPLs excited in different diamond grains. For instance, with regard to the FR23 EFPCD sample, the emission lines at $1.705 \mathrm{eV}(727 \mathrm{~nm}), 1.686 \mathrm{eV}(736 \mathrm{~nm})$, $1.6 \mathrm{eV}(775 \mathrm{~nm})$, and $1.584 \mathrm{eV}(783 \mathrm{~nm})$ have been observed in the No. FR23-1 diamond grain and their intensities increase obviously from surface $(0 \mu \mathrm{m})$ to $-200 \mu \mathrm{m}$, but all of them are absent in the FR23-3 diamond grain.

Although the changing regularities of the PL intensities of $2.313 \mathrm{eV}(535.9 \mathrm{~nm}), 2.153 \mathrm{eV}(575 \mathrm{~nm})$, and $2.024 \mathrm{eV}$ $(613 \mathrm{~nm})$ ZPLs are similar from the surface to deep samples in the same point of the sample, the observed trends are different in different points of the sample (Figure 5). For example, with regard to the FR23 EFPCD sample, the PL intensities of $2.313 \mathrm{eV}(535.9 \mathrm{~nm}), 2.153 \mathrm{eV}(575 \mathrm{~nm})$ and $2.024 \mathrm{eV}(613 \mathrm{~nm})$ ZPLs are increasing from $0 \mu \mathrm{m}$ to $-100 \mu \mathrm{m}$ and decreasing from $-100 \mu \mathrm{m}$ to $-200 \mu \mathrm{m}$ in the 1 diamond grains (FR23-1), but the changing regularities of the PL intensities of them are complex in the 3 diamond grains (FR23-3) (Figures 5(a) and 5(b)). Diamond Raman line is approximately decreasing from the surface to deep samples in all samples.

\section{Discussion}

On the surface of diamond grains of the EFPCDs, abundant growth lamellae and zigzag strips imply that the EFPCDs were fast formed in carbon supersaturation condition. Sharp-edged and plane-faced diamond grains indicate that there was not any remarkable dissolution process during the formation of the EFPCDs. In this scenario, it is possible that the EFPCDs were fast formed shortly before the kimberlite eruption just like the framesites from the Venetia kimberlite in South Africa [7]. Based on the facts that the $1.686 \mathrm{eV}$ $(736 \mathrm{~nm})$ emission line observed in all types of irradiated diamonds [16] is present in the FR23-1 and absent in the FR23-3 diamond grains and the observed trends of the PL intensities of $2.313 \mathrm{eV}(535.9 \mathrm{~nm}), 2.153 \mathrm{eV}(575 \mathrm{~nm})$, and $2.024 \mathrm{eV}(613 \mathrm{~nm})$ ZPLs are different in different points of the sample, it can be concluded that the different diamond grains of the FR23 EFPCD were formed in different environments. Also, it indicates that the EFPCDs were not formed in diamond nucleation stage, but in the diamond growth period. To some extent, this conclusion is also supported by the facts that the centers of some diamond grains are included in other diamond grains, whereas those of the others are not.

On the surface of the ARPCDs, irregular pits, circular striations, protruding guttate overgrown hillocks, and so forth imply that the ARPCDs underwent a notable dissolution process during their formation. At the same time, abundant interstitial pores and cavities indicate that fluids or melts participated in their formation or modified them during the period of their storage in the mantle. From 


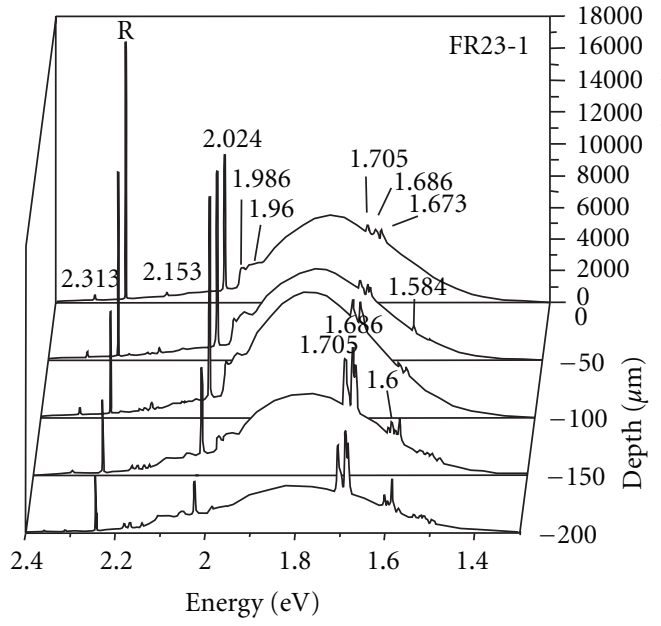

(a)

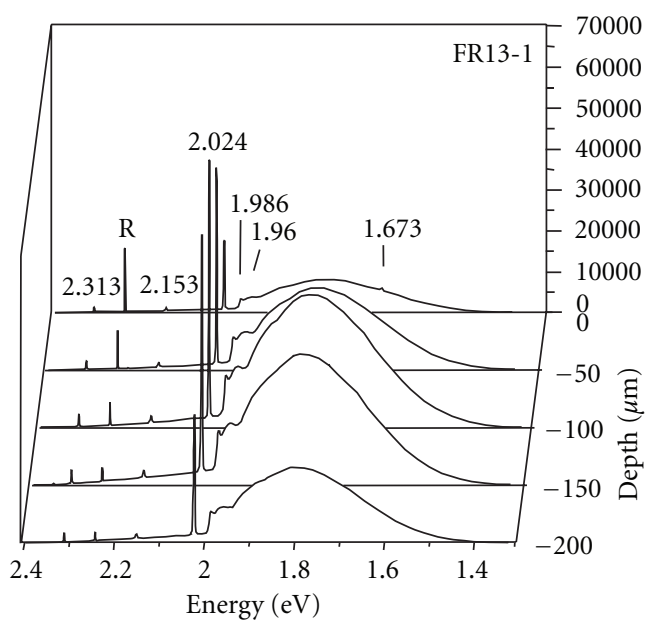

(c)

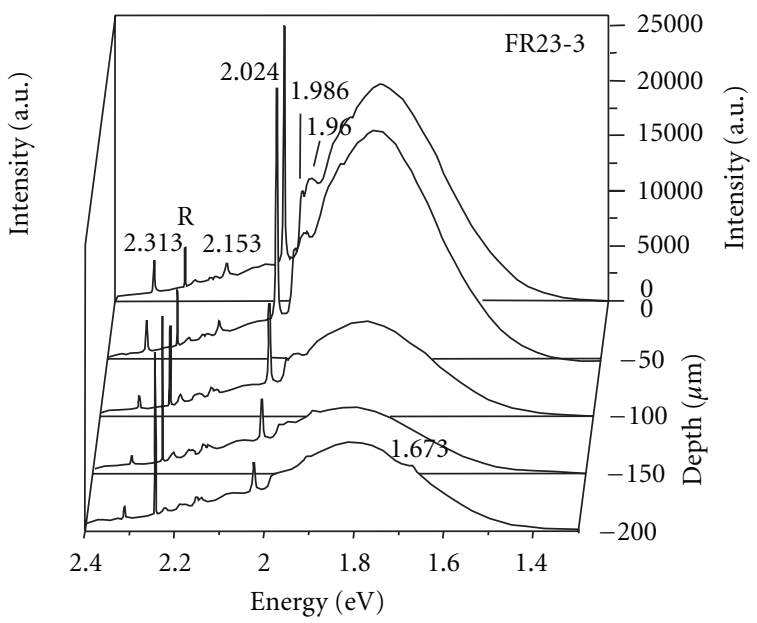

(b)

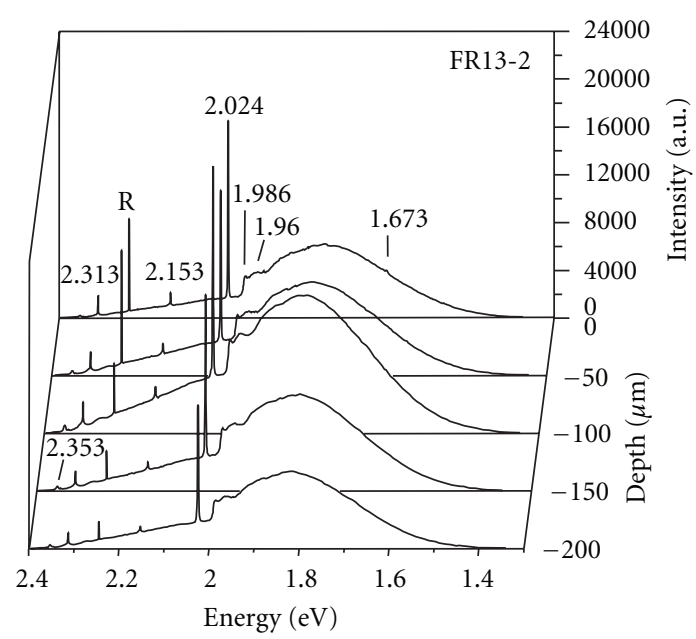

(d)

FIGURE 4: Typical PL spectra of the polycrystalline diamonds from the Mengyin kimberlite pipes ((a) and (b) EFPCDs; (c) and (d) ARPCDs).

the surface to deep sample FR13, the different changing regularities of the PL intensities of $2.313 \mathrm{eV}(535.9 \mathrm{~nm})$, $2.153 \mathrm{eV}(575 \mathrm{~nm})$, and $2.024 \mathrm{eV}(613 \mathrm{~nm}) \mathrm{ZPLs}$ in different points of the sample (Figures 5(c) and 5(d)) suggest that the different parts of the ARPCDs are probably formed in different conditions. Namely, they are formed in different times or spaces. So it is not likely that the ARPCDs are formed in diamond nucleation stage, but in the diamond growth period.

Although the hydrogen-related and nitrogen-related absorption peaks imply that all of the samples were formed in the conditions containing nitrogen and hydrogen, the discrepancy in the FTIR intensities of the peaks demonstrates that the concentrations of nitrogen and hydrogen or the formation processes of the samples are different. It is worth further noticing that the nitrogen originally enters the lattice of diamond in the form of single substitutional (Ccenters) nitrogen. Then the existing form of the nitrogen is gradually transformed from the single substitutional (Ccenters) nitrogen to nitrogen pairs (A-centers) to " $4 \mathrm{~N}+\mathrm{V}$ "
(B-center) at a certain temperature and pressure. Furthermore, in geosciences the degree of nitrogen aggregation $(\mathrm{C} \rightarrow \mathrm{A} \rightarrow \mathrm{B}$ conversion $)$ is used to investigate the timetemperature history of diamond storage in the mantle. The function equation is $K t=1 / C_{1}-1 / C_{0}, K=A \cdot \exp (-E / R T)$ ( $t$ : time; $C_{0}$ and $C_{1}$ : initial and final concentration of single nitrogen or nitrogen pair; $T$ : temperature; $E$ : active energy; $A$ and $R$ : constant) $[17,18]$. Based on the facts that almost all researchers attribute the fine grain size of framesites to rapid crystallization in localized areas of the mantle [2], the ARPCDs are probably formed at a higher temperature than the EFPCDs because there are more Bcenters in the ARPCDs. Consequently, the ARPCDs contain finer octahedral grains. At the same time, the abundant dissolution imprints in the ARPCDs indicate that the storage of the ARPCDs in the mantle is longer than that of the EFPCDs. In addition, the facts that the B-centers are present in the FR6-1 and FR6-3 diamond grains and absent in the FR6-2 and FR6-4 diamond grains indicate that the different diamond grains of the FR6 EFPCD were formed in different 


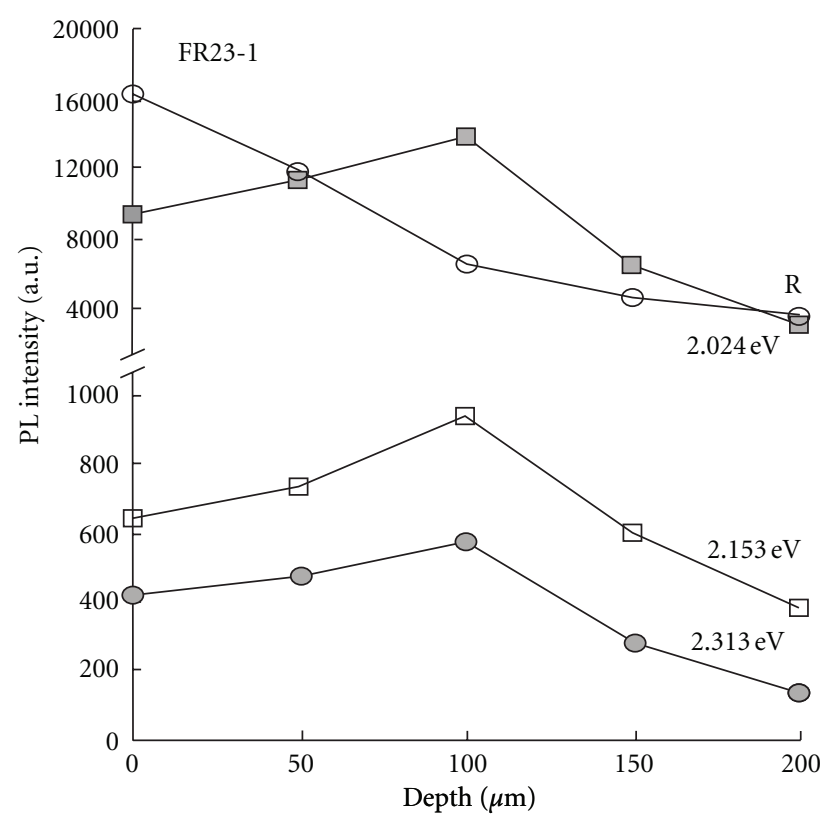

(a)

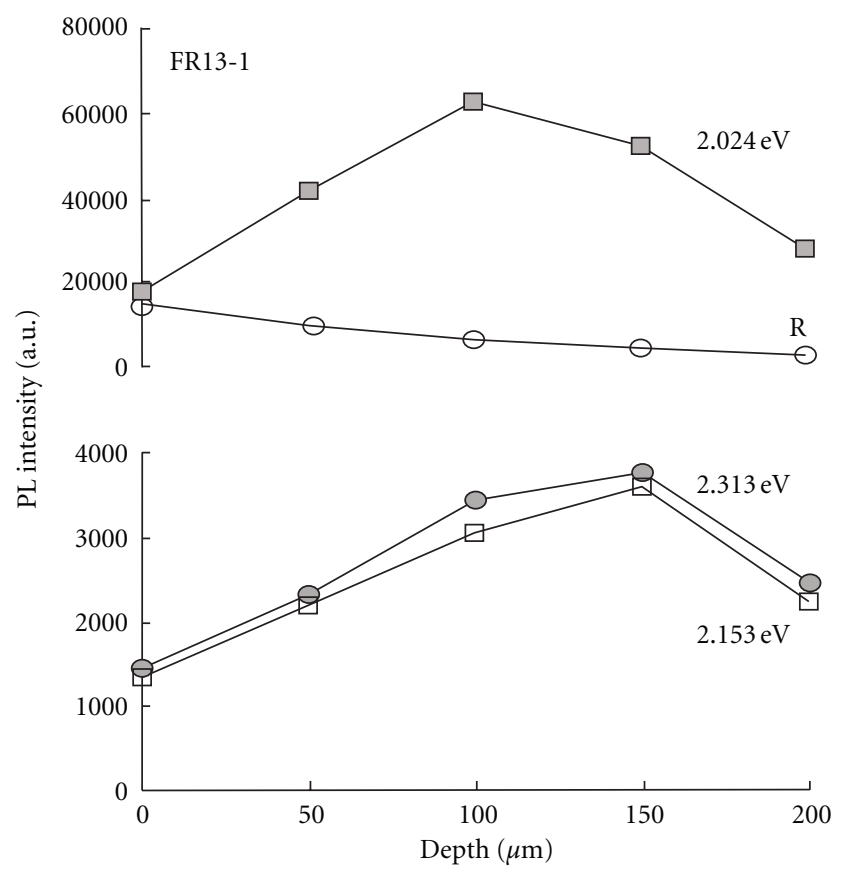

(c)

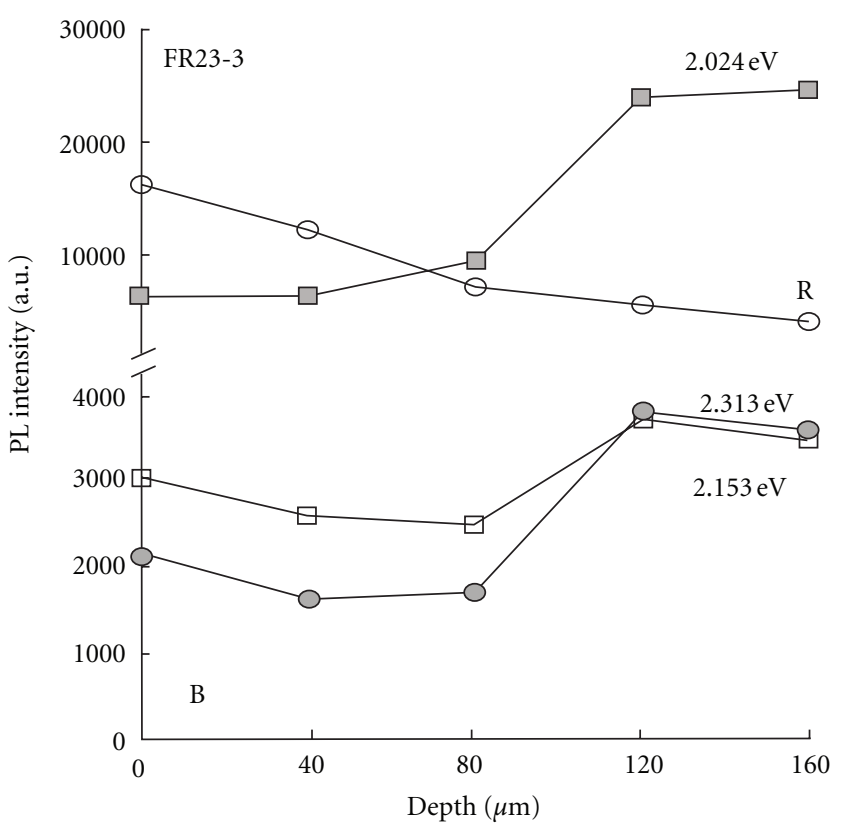

(b)

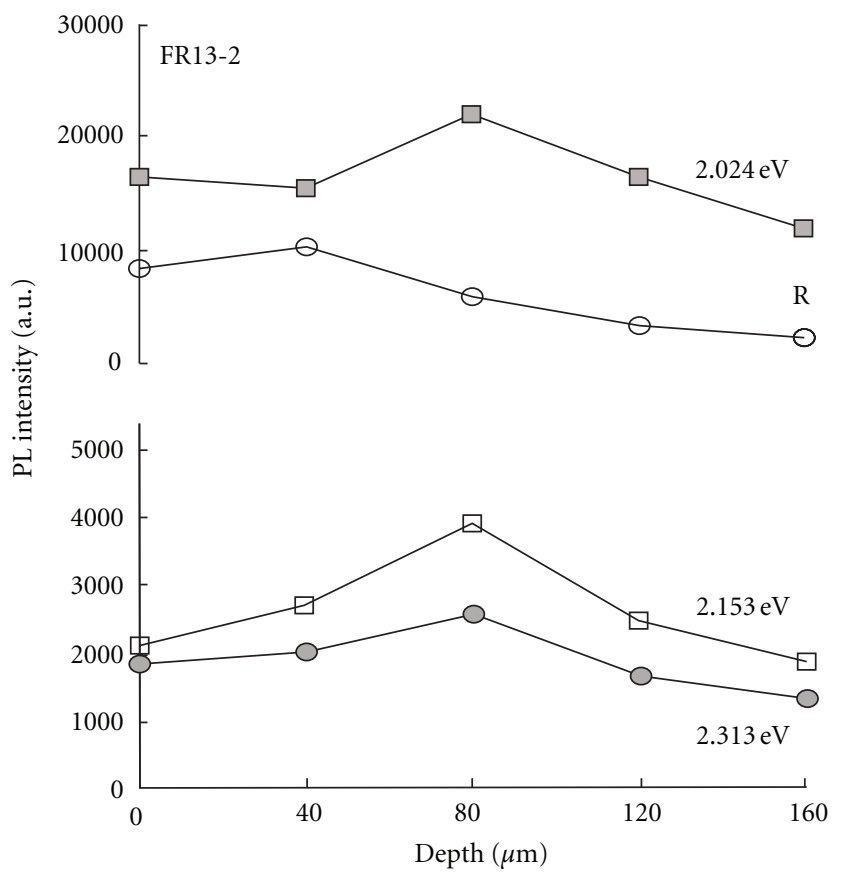

(d)

FIgURE 5: The changing regularities of the PL intensities of $2.313 \mathrm{eV}(535.9 \mathrm{~nm}), 2.153 \mathrm{eV}(575 \mathrm{~nm}), 2.024 \mathrm{eV}$ (613 nm) ZPLs and diamond Raman line of the polycrystalline diamonds from the Mengyin kimberlite pipes ((a) and (b) EFPCDs; (c) and (d) ARPCDs).

environments. As a result, the EFPCDs were not formed in diamond nucleation stage, but in the diamond growth period. Similarly, the facts that the B-centers are present in points FR49-2 and FR49-3 and A-center is present in point FR49-1 imply that the different parts of the ARPCDs were formed in different conditions and were not probably formed in diamond nucleation stage either.

As mentioned above, the content of nitrogen is generally low in the samples. The present authors think this might be related to the low nitrogen concentration environment during the formation of the samples. In general, nitrogen concentrations in diamond are related to the growth velocity of diamond and/or environmental nitrogen concentrations [19]. Theoretically, as an impurity, nitrogen should be affected by the "impurity clearing" process of diamond structure. Obviously, under high growth velocity of the diamond, the impurity clearing of nitrogen is blocked, nitrogen defects increase, and, as a result, the nitrogen 
concentrations become higher. Namely, the nitrogen concentrations in diamond and the growth velocity of diamond show positive correlation. This is the main reason why previous studies concluded that the nitrogen concentrations are higher in fibrous diamonds than high-quality octahedral peridotitic $(P)$ type and eclogitic $(E)$ type diamond single crystals $[20,21]$. In this scenario, crystallization velocity is not the decisive factor for the low nitrogen concentrations in the samples, instead low environmental nitrogen concentrations are the key parameter. Previous research results demonstrate that the nitrogen concentrations were $2 \sim 40 \mathrm{ppm}$ in the mantle and displayed a diminishing trend from shallow to deep mantle $[19,22]$. So the nitrogen concentrations could be used to determine the relative original depth in mantle of the diamond. For instance, based on the quite high nitrogen concentrations, the cubic diamonds from the Jwaneng kimberlite were thought to have originated from the shallow mantle [23]. In addition, the content of nitrogen is generally higher in the eclogitic $(E)$ type diamond single crystals than in the peridotitic $(P)$ type crystals. From the above, the present authors think that the samples from Mengyin kimberlite pipes probably originate from relatively deeper mantle and are formed in the environment like the peridotitic $(P)$ type diamond single crystals.

\section{Conclusions}

Different diamond grains or points of the samples were formed in different conditions or processes. The samples were not formed in diamond nucleation stage, but in the diamond growth period.

The samples probably originated from relatively deeper mantle and were formed in the environment like the peridotitic $(P)$ type diamond single crystals. The EFPCDs did not undergo a significant dissolution process during their formation and were possibly fast formed shortly before the kimberlite eruption. The ARPCDs were formed at a higher temperature than the EFPCDs, underwent a notable dissolution process, and had been stored relatively longer in the mantle. Fluids or melts probably participated in the formation of the ARPCDs or modified them during the period of their storage in the mantle.

Finally, the results of our study demonstrate that the polycrystalline diamonds are authentically an inhomogeneous system. So recovering the history of nucleation and growth of polycrystalline diamonds would be the basis of further study of the formation and origin of them.

\section{Acknowledgments}

The authors gratefully acknowledge support for the work by Grant no. 41073021 from the Natural Science Foundation of China, Grant no. 9151027501000088 from the Guangdong Provincial Natural Science Foundation, and Grant no. 11 lgpy02 from the Fundamental Research Funds for the Central Universities.

\section{References}

[1] Y. L. Orlov, The Mineralogy of the Diamond, John Wiley \& Sons, New York, NY, USA, 1977.

[2] P. J. Heaney, E. P. Vicenzi, and S. De, "Strange diamonds: the mysterious origins of carbonado and framesite," Elements, vol. 1, no. 2, pp. 85-89, 2005.

[3] G. J. H. McCall, "The carbonado diamond conundrum," Earth-Science Reviews, vol. 93, no. 3-4, pp. 85-91, 2009.

[4] G. Dobosi and G. Kurat, "Trace element abundances in garnets and clinopyroxenes from diamondites-a signature of carbonatitic fluids," Mineralogy and Petrology, vol. 76, no. 1-2, pp. 21-38, 2002.

[5] G. Dobosi and G. Kurat, "On the origin of silicate-bearing diamondites," Mineralogy and Petrology, vol. 99, no. 1, pp. 2942, 2010.

[6] T. Irifune, A. Kurio, S. Sakamoto, T. Inoue, H. Sumiya, and K. I. Funakoshi, "Formation of pure polycrystalline diamond by direct conversion of graphite at high pressure and high temperature," Physics of the Earth and Planetary Interiors, vol. 143-144, pp. 593-600, 2004.

[7] D. E. Jacob, K. S. Viljoen, N. Grassineau, and E. Jagoutz, "Remobilization in the cratonic lithosphere recorded in polycrystalline diamond," Science, vol. 289, no. 5482, pp. 1182$1185,2000$.

[8] D. E. Jacob, R. Wirth, F. Enzmann, J. O. Schwarz, and A. Kronz, "Constraints on presses of diamond formation from inclusions in polycrystalline diamond (Framesite)," in Proceedings of the 9th International Kimberlite Conference Extended Abstract (IKC '08), 2008, Abstract no. 9IKC-A-00159.

[9] T. Maruoka, G. Kurat, G. Dobosi, and C. Koeberl, "Isotopic composition of carbon in diamonds of diamondites: record of mass fractionation in the upper mantle," Geochimica et Cosmochimica Acta, vol. 68, no. 7, pp. 1635-1644, 2004.

[10] R. Burgess, L. H. Johnson, D. P. Mattey, J. W. Harris, and G. Turner, "He, Ar and C isotopes in coated and polycrystalline diamonds," Chemical Geology, vol. 146, no. 3-4, pp. 205-217, 1998.

[11] M. Honda, D. Phillips, J. W. Harris, and I. Yatsevich, "Unusual noble gas compositions in polycrystalline diamonds: preliminary results from the Jwaneng kimberlite, Botswana," Chemical Geology, vol. 203, no. 3-4, pp. 347-358, 2004.

[12] W. Wang, E. Takahashi, and S. Sueno, "Geochemical properties of lithospheric mantle beneath the Sino-Korea craton; evidence from garnet xenocrysts and diamond inclusions," Physics of the Earth and Planetary Interiors, vol. 107, no. 1-3, pp. 249-260, 1998.

[13] T. Jiang and K. Xu, "FTIR study of ultradispersed diamond powder synthesized by explosive detonation," Carbon, vol. 33, no. 12, pp. 1663-1671, 1995.

[14] J. E. Field, The Properties of Natural and Nynthetic Diamond, Academic Press, London, UK, 1992.

[15] Y. F. Meng, C. S. Yan, J. Lai et al., "Enhanced optical properties of chemical vapor deposited single crystal diamond by low-pressure/high-temperature annealing," Proceedings of the National Academy of Sciences of the United States of America, vol. 105, no. 46, pp. 17620-17625, 2008.

[16] A. M. Zaitsev, Optical Properties of Diamond: A Data Handbook, Springer, Berlin, Germany, 2001.

[17] R. M. Chrenko, R. E. Tuft, and H. M. Strong, "Transformation of the state of nitrogen in diamond," Nature, vol. 270, no. 5633, pp. 141-144, 1977.

[18] Z. Yang, H. Li, M. Peng, J. Chen, F. Lin, and Y. Su, "Study on the HPHT synthetic diamond crystal from $\mathrm{Fe}-\mathrm{C}(\mathrm{H})$ system 
and its significance," Chinese Science Bulletin, vol. 53, no. 1, pp. 137-144, 2008.

[19] P. Cartigny, J. W. Harris, and M. Javoy, "Diamond genesis, mantle fractionations and mantle nitrogen content: a study of $\delta^{13} \mathrm{C}-\mathrm{N}$ concentrations in diamonds," Earth and Planetary Science Letters, vol. 185, no. 1-2, pp. 85-98, 2001.

[20] O. Navon, I. D. Hutcheon, G. R. Rossman, and G. J. Wasserburg, "Mantle-derived fluids in diamond micro-inclusions," Nature, vol. 335, no. 6193, pp. 784-789, 1988.

[21] S. R. Boyd, F. Pineau, and M. Javoy, "Modelling the growth of natural diamonds," Chemical Geology, vol. 116, no. 1-2, pp. 29-42, 1994.

[22] B. Harte and J. W. Harris, "Lower mantle mineral associations preserved in diamonds," Mineralogical Magazine A, vol. 58, pp. 384-386, 1994.

[23] P. Deines, J. W. Harris, and J. J. Gurney, "Carbon isotope ratios, nitrogen content and aggregation state, and inclusion chemistry of diamonds from Jwaneng, Botswana," Geochimica et Cosmochimica Acta, vol. 61, no. 18, pp. 3993-4005, 1997. 


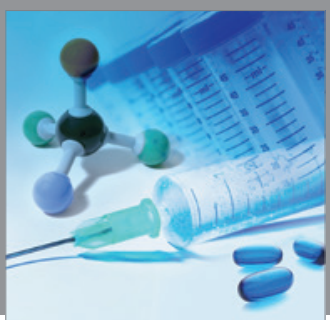

International Journal of

Medicinal Chemistry

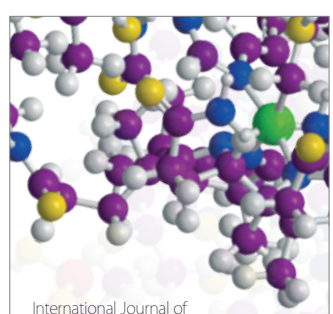

Carbohydrate Chemistry

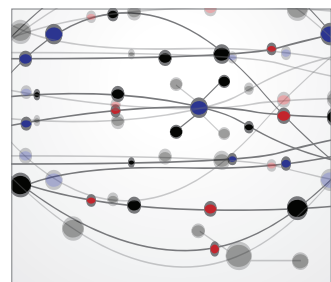

The Scientific World Journal
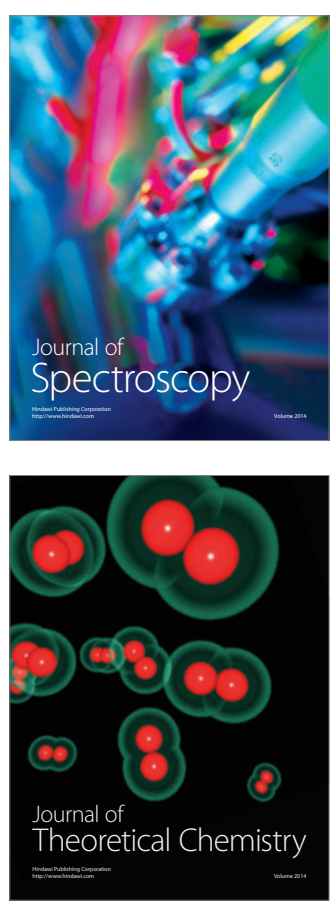
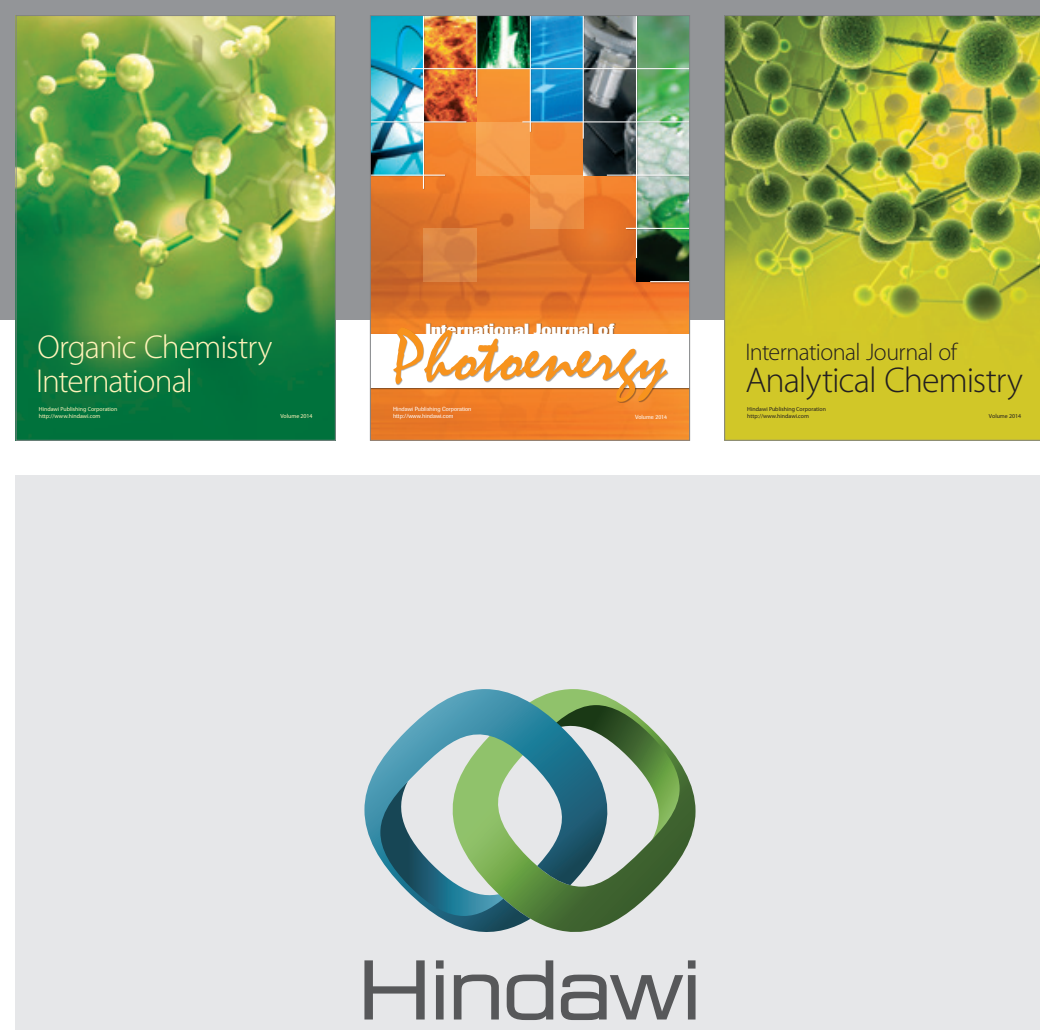

Submit your manuscripts at

http://www.hindawi.com
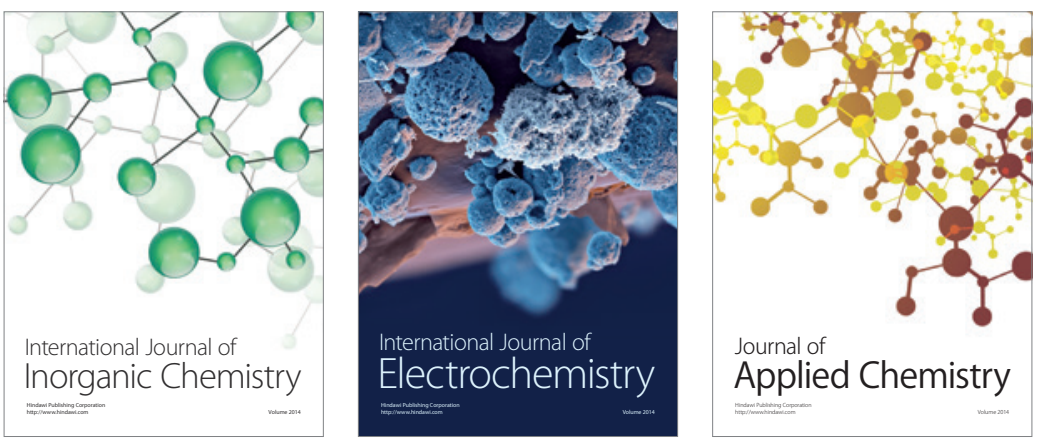

Journal of

Applied Chemistry
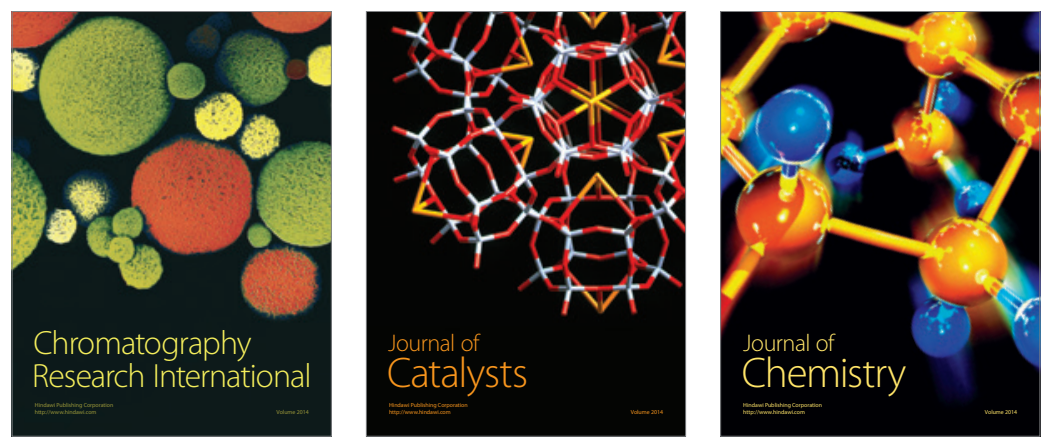
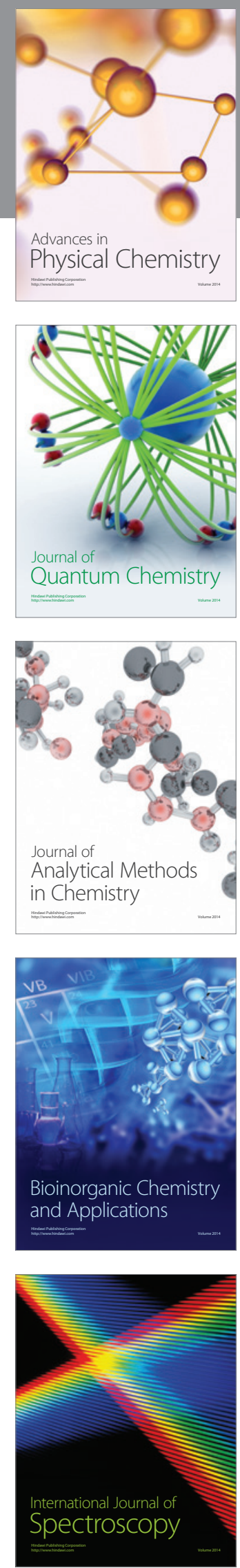